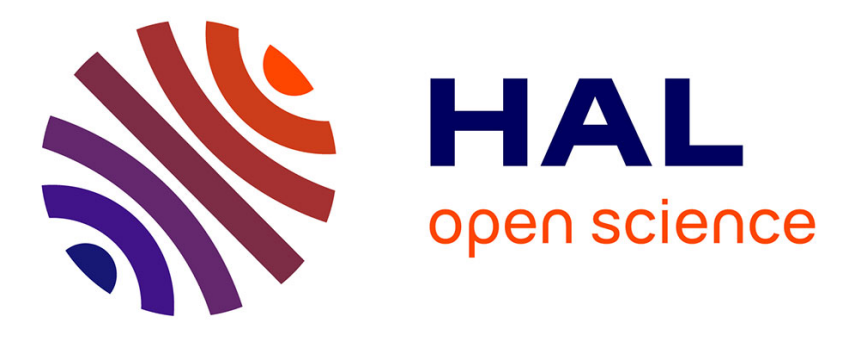

\title{
Designing Controversies and Their Publics
}

\author{
Tommaso Venturini, Donato Ricci, Michele Mauri, Lucy Kimbell, Axel \\ Meunier
}

\section{To cite this version:}

Tommaso Venturini, Donato Ricci, Michele Mauri, Lucy Kimbell, Axel Meunier. Designing Controversies and Their Publics. Design Issues, 2015, 31 (3), pp.74-87. 10.1162/DESI_a_00340 . hal01672300

\section{HAL Id: hal-01672300 https://hal.science/hal-01672300}

Submitted on 23 Dec 2017

HAL is a multi-disciplinary open access archive for the deposit and dissemination of scientific research documents, whether they are published or not. The documents may come from teaching and research institutions in France or abroad, or from public or private research centers.
L'archive ouverte pluridisciplinaire HAL, est destinée au dépôt et à la diffusion de documents scientifiques de niveau recherche, publiés ou non, émanant des établissements d'enseignement et de recherche français ou étrangers, des laboratoires publics ou privés. 


\section{Designing Controversies and Their Publics \\ Tommaso Venturini, Donato Ricci, Michele Mauri, Lucy Kimbell, Axel Meunier}

Figure 1

Two maps both unsatisfactory but for opposite reasons. (Daniele Guido, Sciences Po médialab)
1 Bruno Latour, "La cartographie des controverses," Technology Review, N. 0: 82-83.

2 See, for example, the work done by Albena Yaneva on architectural controversies at Manchester, Mapping Controversies in Architecture (Manchester: Ashgate Publishing Company, 2012). Other cities in which $\mathrm{CM}$ is taught include Paris, Copenhagen, Milan, Amsterdam, Liège, Lausanne, Padova, Trento, Buenos Aires, and Rio de Janeiro.

3 For example, see MACOSPOL (mappingcontroversies.net), MEDEA (projetmedea. hypotheses.org), and EMAPS (climaps.eu, emapsproject.com), FORCCAST (forccast. hypotheses.org).

4 Cfr. Yves Lacoste, La Géographie, Çà Sert, D'abord, À Faire La Guerre [Geography is First and Foremost at the Service of War] (Paris: La Decouverte, 1976).

5 All the beautiful images that illustrate this paper (except for Figures 3 to 8 ) have been designed by Daniele Guido.

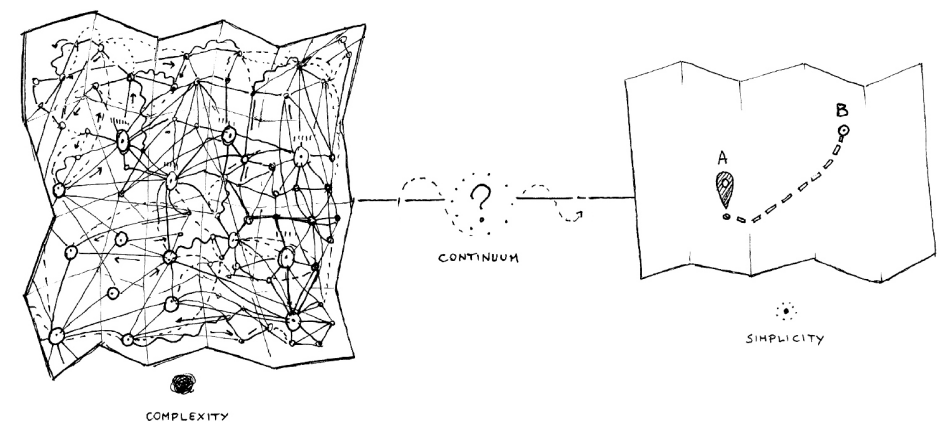

Asking the Right Question

Twenty years ago, Bruno Latour conceived Controversy Mapping $(\mathrm{CM})$ as a method to train students in the observation and description of sociotechnical debates. ${ }^{1}$ Since then, CM has evolved considerably, not only because of the many universities that have adopted and adjusted it to their context, ${ }^{2}$ but also because CM has become the pivot point of several international research projects. ${ }^{3}$

Since the very beginning of this enterprise, it has been clear that the main challenge for the method was to engage with actors of the controversies. To be sure, CM is not a method of social intervention. Unlike crisis management or conflict resolution, it is not meant to solve or channel debates (nor does it assume such intervention is always desirable). Yet, as extensively shown in geography, maps are never neutral representations. ${ }^{4}$ Cartography has always been a political tool and CM is not an exception. So, how could our tools and methods enhance democracy? What use will the public make of our maps? How can mapping improve the debate on science and technology?

At the end of the first international research project on controversy mapping, MACOSPOL (Mapping COntroversies on Science for POLitics), we gathered a group of journalists and policy makers to beta-test our results. We discovered that they could make little use of our maps. We were facing a classical tradeoff in cartography: We could either offer maps that are rich but difficult to read, or maps that are easy to read but poor in content (see Figure 1). ${ }^{5}$ This trade-off between richness and legibility 
6 Tommaso Venturini, "Diving in Magma: How to Explore Controversies with Actor-Network Theory," Public Understanding of Science 19, no. 3 (May 29, 2010): 258-73.

7 Tommaso Venturini, "Building on Faults: How to Represent Controversies with Digital Methods," Public Understanding of Science 21, no. 7 (December 05, 2012): 796-812.

8 Readers probably know the famous short story by Jorge Luis Borges, On The Exactitude in Science, but they may ignore an earlier version in Lewis Carroll's Sylvie and Bruno Concluded (1893): "Then came the grandest idea of all! We actually made a map of the country, on the scale of a mile to the mile!" "Have you used it much?" I inquired. "It has never been spread out, yet," said Mein Herr: "the farmers objected: they said it would cover the whole country, and shut out the sunlight! So we now use the country itself, as its own map, and I assure you it does nearly as well."

9 EMAPS is financed by the "Sciences in Society" call for project of the 7th Framework Programme of the European Union.

10 Bruno Latour, "A Cautious Prometheus? A Few Steps Toward a Philosophy of Design (with Special Attention to Peter Sloterdijk," Conference of the Design History Society (UK: September 2008).

11 Following this lead, we made sure that the EMAPS consortium included partners with competences in communication design (DensityDesign Lab, Milan) and community design (The Young Foundation, London).

12 By "issue-expert" we mean all persons having a relevant experience of a given controversy. By definition, all actors engaged in a controversy are also experts of it.

13 See http://medialab.sciences-po.fr.

14 See https://www.digitalmethods.net.

15 See http://www.densitydesign.org. mirrors another tension that we have already encountered in working with controversies: the tension between the wish to observe controversies in their unreduced complexity, ${ }^{6}$ and the desire to make them understandable for a wider public. ${ }^{7}$ Both of these objectives are crucial to our endeavor: If we oversimplify the richness of controversies, we lose all their interest; if we simplify too little, the map becomes as large as the territory and therefore useless. ${ }^{8}$ To cope with this conundrum, we started another collaborative research project: Electronic Maps to Assist Public Science (EMAPS). ${ }^{9}$ This time, we took two precautions to make our experiment safer. First, we searched backup beyond the frontiers of science and technology studies (where CM originated) in the discipline that is most essentially concerned with the question of legibility and community engagement: design. The idea that design could be crucial in CM had been advanced by Latour himself in 2008 while addressing the Design History Society in Falmouth:

In its long history, design practice has done a marvelous job of inventing the practical skills for drawing.... But what has always been missing from those marvelous drawings (designs in the literal sense) is an impression of the controversies and the many contradicting stakeholders that are born within with these...

So here is the question I wish to raise to designers: Where are the visualization tools that allow the contradictory and controversial nature of matters of concern to be represented? ${ }^{10}$

Through design, we hoped we could find the right point of balance between legibility and complexity. ${ }^{11}$ Once again, however, things turned out to be more complicated than expected.

In June 2012, EMAPS organized in London its first encounter with potential users. The meeting was centered on the questions related to aging and was attended by about 35 "issueexperts." 12 Our workshop methodology was to seat participants at tables in mixed teams of about six people, each with at least one EMAPS researcher and one facilitator. The visualizations employed in the workshop were drawn from a set of 25 printed maps produced by researchers at the Sciences Po médialab ${ }^{13}$ and the Digital Methods Initiative ${ }^{14}$ and redesigned by the DensityDesign Lab. ${ }^{15}$

Unfortunately, our design efforts did not result in a dramatic improvement in our capacity to engage with the public. The responses to the maps showed a polite confusion, which was not just a matter of data visualization, but rather of difficulty in grappling with what the maps were and how they might relate to the users' worlds. Maps still remained too difficult to read or too poor in content. Even worse, different testers found opposite faults in the same maps depending on the singular characteristics of the users, the maps, and the user-map combination. 
Figure 2

The three sections of the first movement along the complexity/simplicity continuum. (Daniele Guido, Sciences Po médialab)
16 cfr. Walter Lippmann, The Phantom Public (New York: The Macmillan Company, 1927) and John Dewey, The Public and Its Problems: An Essay in Political Inquiry (Chicago, IL: Gateway Books, 1946).

17 Dewey 1946, 33, 137.

18 Far from being a mere juxtaposition of maps, good atlases allow their users to move through their charts. First used in 1595 as the title for a series of maps by Gerhard Mercator (Atlas, or Cosmographical Meditations upon the Creation of the Universe), the term "atlas" has known an increasing fortune and an immense array of applications. From history to politics, from arts to medicine, from astrology to psychology, the atlas is a systematic bind of representations relative to a specific but

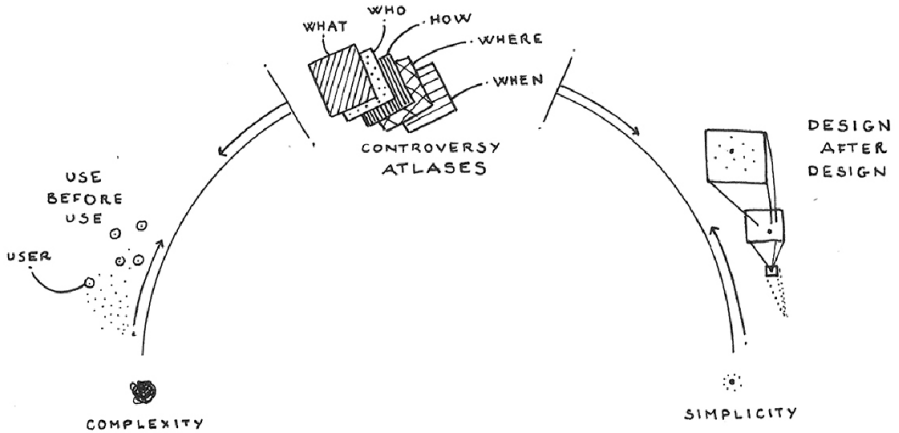

Although inconvenient, such a conclusion is not inconsistent with the political theories that inspired CM. If there is something that controversy mapping has learned from American pragmatism is that there is no such a thing as a homogeneous public. ${ }^{16}$

In no two ages or places is there the same public.

Conditions make the consequences of the associated action and the knowledge of them different. It is not that there is no public... There is too much public, a public too diffused and scattered and too intricate in composition. And there are too many publics. ${ }^{17}$

As in the title of Walter Lippmann's famous book The Phantom Public, the public is a phantom or rather a gaggle of ghosts provisionally assembled around a specific issue and by no means made uniform by it. We knew that each controversy affected differently each of the actors involved; we only had to realize that the level of complexity that each actor is willing to handle varies accordingly. This reflection helped us to realize that we might have been asking the wrong question all along. Instead of asking where we should stand in the legibility/complexity continuum, we should have asked how we could move through it.

Luckily, with EMAPS we had taken a second precaution: We decided to schedule the first user test very early-a few months after the beginning of the project. This precaution gave us the time to explore the room for maneuvering opened up by replacing the question of balance with the question of movements. Archived the chase for an impossible equilibrium, EMAPS ultimately offered a more interesting exercise: cataloging the various ways of walking the tightrope of controversies. The rest of the article describes the three movements on which CM should be based.

\section{The First Movement of Controversy Design: Extending the Complexity/Legibility Trade-Off}

The first movement we identified aims at extending the range of the complexity/legibility trade-off, allowing researchers and users to move along the imaginary continuum illustrated in Figure 2. This movement is threefold because it can go from the center to the ends or from each end toward the center. 


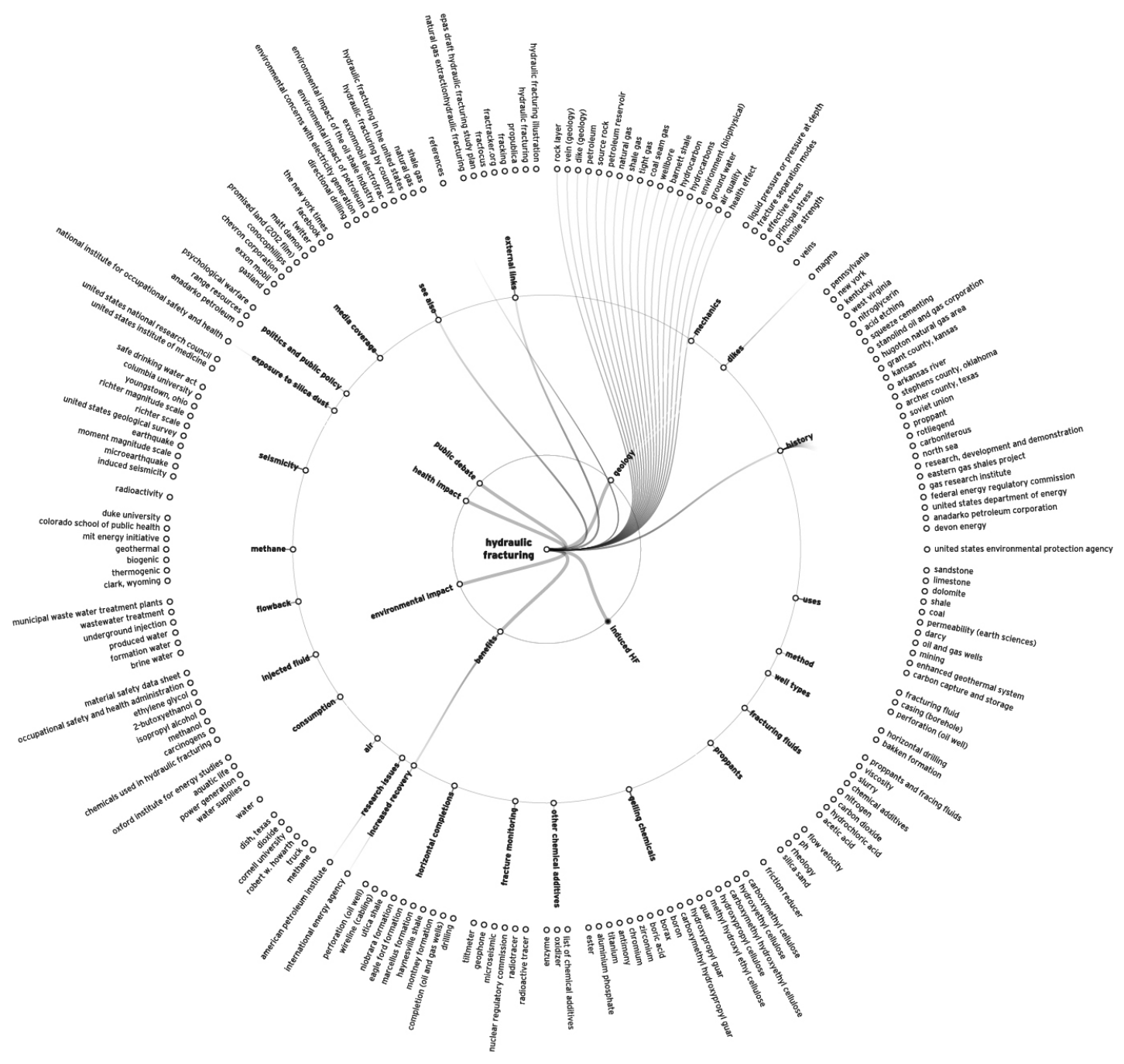

Figure 3

An example of tree of disagreement tree.

(Chiara Andreossi, Massimo Guizzetti, Cristina

Palamini, Giulia Peretti, Silvia Recalcati,

Politecnico di Milano, Density Design)

heterogeneous universe of objects. Marco Quaggiotto, "A New Atlas for Abstract Spaces: Visual Tools for the Exploration of Complex Contexts," in DRS2010 - Design \& Complexity Proceedings, ed. David Durling et al. (Montreal, 2010).

19 Donato Ricci, “Seeing What They Are Saying: Diagrams for Socio-Technical Controversies," in DRS2010 - Design \& Complexity Proceedings, ed. David Durling et al. (Montreal, 2010).
Movement One, Section One: Easing into Complexity Through Controversy Atlases

The first section of this movement (from the center to the ends) simply consists of a series of visualizations with different degrees of complexity. The concept of "atlas" is important here: ${ }^{18}$ As the mythological figure from which they borrow their name, atlases bear a reality and provide it with meaning. An atlas is the result of two distinct actions: going in-the action of observing, by which we try to get in contact with a subject-and going out - the action of telling, by which we reconnect and compose the elements we observed. An atlas-and a fortiori, a controversy atlas-is a container of different points of view, ${ }^{19}$ expressed through different scales and granularities, languages and techniques of representation. No single map can keep together the complexity of social debate and make it legible, but many maps gathered in an atlas might succeed. 

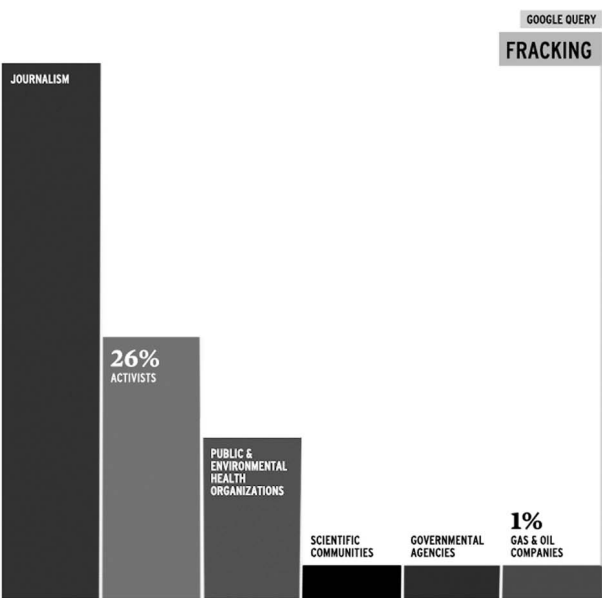

Figure 4

An example of actor-argument table.

(Chiara Andreossi, Massimo Guizzetti, Cristina Palamini, Giulia Peretti, Silvia

Recalcati, Politecnico di Milano,

Density Design)
20 Venturini, 2010.

21 Venturini, 2012

22 In the following pages, we provide examples taken from the work done by one of our best groups of students on the hydraulic fracturing/fracking controversy (http://www.whatthefrack.eu/). Figures 3 to 7 have been designed by Chiara Andreossi, Massimo Guizzetti, Cristina Palamini, Giulia Peretti, and Silvia Recalcati. Their extraordinary research report is available here: http://issuu.com/densitydesign/docs/whatthefrack/15 $9 ?=1199872 / 2100124$

23 Of course, as Umberto Eco noted, taxonomies are always more complex than expected, and the branching of arguments resembles more to a rizhome than to a simple Porphyrian Tree. (Umberto Eco. Semiotica e filosofia del linguaggio. [Semiotics and the Philosophy of Language] (Torino: Einaudi, 1984), 58-64.

24 Recall that $\mathrm{CM}$, descending from actornetwork theory, has a very extensive definition of actors: scientists and engineers, of course, but also lay experts, activists, and decision makers, and not only individual actors but also collective actors (e.g., research institutions, enterprises, lobbies) and non-human actors (e.g., instruments, theories, laws, natural
In two previous articles, we described a path through the complexity of controversies ${ }^{20}$ and a series of controversy maps. ${ }^{21}$ In this article we put them together to describe a possible first section to our first movement. ${ }^{22}$

1. From statements to debates (what). The goal of this section is to show that statements in controversies are never isolated, but always connected in a dialogue made of endorsements and oppositions. Among the many ways to do so, the most popular among the students of controversy mapping is the "tree of disagreement" (a format as old as Greek philosophy).23 (See conceptual image structure as displayed in Figure 3.)

2. From debates to actors (who). The second goal of this section consists of re-attaching the statements to their speakers. Proposing an argument (as well as refuting it) is never a mere intellectual move. In controversies, every speech act binds alliances and entrenches oppositions. Plotting who shares which argument with whom, the "actorsarguments table" is therefore crucial to controversy mapping. ${ }^{24}$ (See Figure 4.)

3. From actors to networks (how). Actors, like statements, are never isolated in controversies. As Latour makes very clear, the hyphen in "actor-network" does not encourage researchers to look at one and then the other, but to consider actors and networks as one thing. ${ }^{25}$ In controversies, their alliances and oppositions determine the position and the actors' identity and, conversely, networks are defined by the actors that they connect. The "actor-network diagram" is meant to visualize the simultaneous movements of individualization and clusterization that characterize controversies. (See Figure 5.) 
Figure 5

An example of actor-network diagram.

(Chiara Andreossi, Massimo Guizzetti,

Cristina Palamini, Giulia Peretti, Silvia

Recalcati, Politecnico di Milano,

Density Design) elements); Michel Callon, "Some elements of a Sociology of Translation: Domestication of the Scallops and the Fishermen of St Brieuc Bay" in John Law (ed.) Power, Action and Belief: A New Sociology of Knowledge (1986), 196-233.

25 Bruno Latour, "On Recalling ANT" in Actor Network and After (Oxford: Blackwell, 1999), 15-25.

how specific controversies might look from the outside, from the viewpoint of their actors, they are a war of words. Conversely, no matter how abstract the principles at stake are, controversies are always decided by the most specific and concrete arrangements.

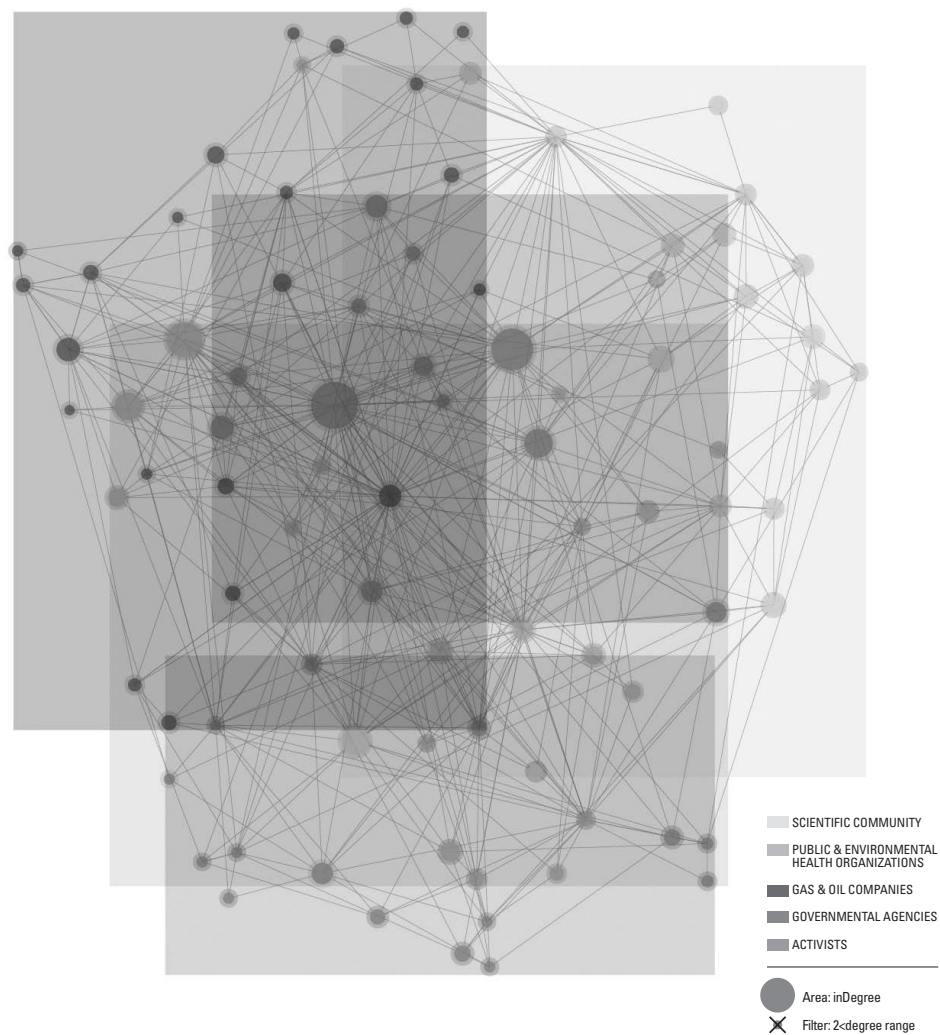

4. From networks to cosmoses (where). Every controversy is always part of other larger meta-controversies and is always composed of several sub-controversies. Cartographers are asked free to choose their level of investigation, but they must be able to situate their case study in the "scale of disputes" to which it belongs: showing, in particular, that controversies, although often fought on the battlefield of technical details, always oppose conflicting worldviews. ${ }^{26}$ (See conceptual image structure as displayed in Figure 6.)

5. From cosmoses to cosmopolitics (when). In addition to presenting what controversies are about, who fights them, and how they join or oppose their forces, cartographers must also show how all these elements evolve through time. Add to this the fact that the time of controversies is often heterogeneous (different parts of the same controversy might remain dormant for ages and suddenly burst into the quickest developments), and the complexity of cosmopolitics becomes evident. (See Figure 7.) 
Figure 6

An example of scale of cosmos. (Chiara Andreossi, Massimo Guizzetti, Cristina Palamini, Giulia Peretti, Silvia Recalcati, Politecnico di Milano, Density Design)

\section{Figure 7}

An example of debate dynamics. (Chiara Andreossi, Massimo Guizzetti, Cristina Palamini, Giulia Peretti, Silvia Recalcati, Politecnico di Milano, Density Design)
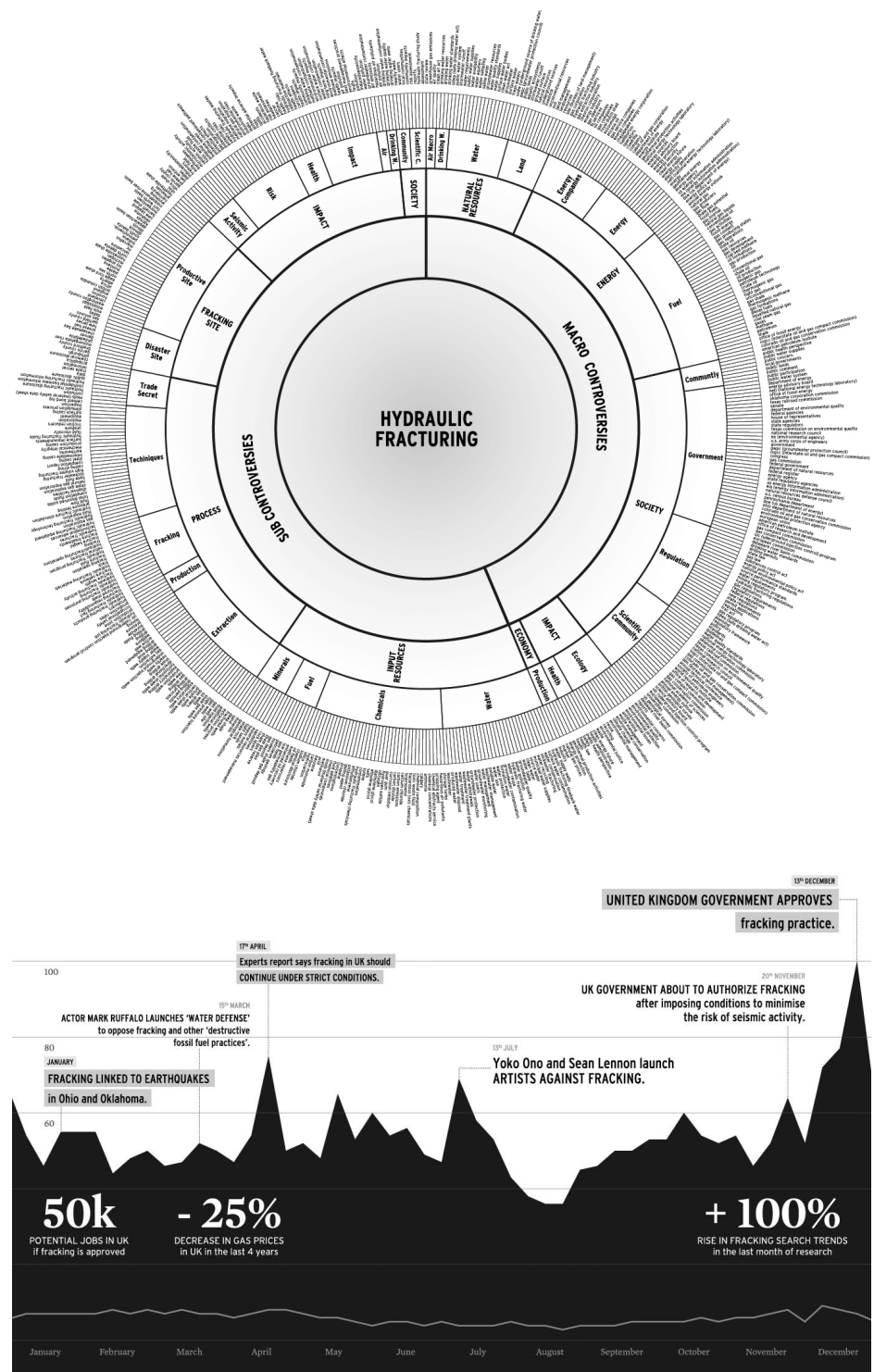

Other concatenations than the one described here certainly would be possible. The important move is to break down the richness of a controversy and then rebuild it through a chain of subsequent representations.

Movement One, Section Two: Use-Before-Use and Participatory Design The second and third sections of the first movement have been conceptualized within the tradition of participatory design. Speaking at the European Association for Study of Science and Technology, Pelle Ehn explicitly discussed Latour's Falmouth challenge and proposed two complementary approaches called "use-beforeuse" and "design-after-design." 
Ehn defines the first approach as follows:

Basically, the idea is to say: well, let's invite users-we know who they are, who the human constituencies areand have them participate and, by that way, envision a future use, and we use all these tools, all scenarios and prototypes to do that. It could be said: to focus on assemblies before objects, and use before actual use. ${ }^{27}$
27 Pelle Ehn, “Design Things: Drawing Things Together and Making Things Public." TECNOSCIENZA 2, no. 1 (2011): 43, 44. http://www.tecnoscienza.net/index. php/tsj/article/view/64.

28 To know more about the work done in EMAPS project on the Aging controversy see http://www.emapsproject.com/blog/ archives/category/ageing-controversies.

29 Ehn, 2011: 46.

30 Pelle Ehn, Work-Oriented Design of Computer Artifacts (Hillsdale, NJ: Lawrence Erlbaum Associates, 1988).

31 Introduced in the field of exploratory data analysis, John W. Tukey, Exploratory Data Analysis (Reading, MA: Addison-Wesley Publishing Company, 1977) interactive data visualizations have been recently proposed for less specialized users; see Zachary Pousman, John Stasko, and Michael Mateas, “Casual Information Visualization: Depictions of Data in Everyday Life," IEEE Transactions on Visualization and Computer Graphics 13, no. 6 (2007). At least four areas of visualization for non-experts have been developed: 1) Ambient visualization, Zachary Pousman and John Stasko, A Taxonomy of Ambient Information Systems, Proceedings of the Working Conference on Advanced Visual Interfaces - AVI '06 [New York, NY: ACM Press, 2006]; 2) Social visualization; 3) Artistic visualization, Fernanda B. Viégas and Martin Wattenberg, "Artistic Data Visualization: Beyond Visual Analytics," (July 22, 2007), 182-91; http://portal. acm.org/citation.cfm?id=1784297. 1784319; and Robert Kosara, Visualization Criticism - The Missing Link Between Information Visualization and Art, 2007 11th International Conference Information Visualization (IV '07) (IEEE, 2007); and 4) Persuasive visualization, B. J. Fogg, "Persuasive Technology: Using Computers to Change What We Think and Do," Ubiquity (December 2002).
To implement the "use-before-use" approach in EMAPS, we organized a second user test. This time, we started by choosing one "issue expert" to work with us as lead user. For this role, we chose one of the participants at the first meeting, Maria Parsons (Creative Dementia Network/Eminence Grise). Between August and October, we spent several days with Maria as a participant observer as she went about her work. The aim of these sessions was to elicit Maria's "research questions" in relation to aging.

On the basis of these observations, EMAPS researchers developed a second set of maps on aging. These maps were then shown to a small group of issue professionals to discuss with them how the design could be improved. In contrast to the June event, in this test we asked the participants to try to use the maps and locate themselves within them, rather than just responding to them.

Drawing on the results of the Oxford meeting, the controversy maps were improved by collecting additional data and enhancing the design. The new set of maps then became the basis for another, larger meeting held in London on December 12, 2012. Compared to the previous occasion, the second London meeting was a clear success. Interacting with the users from the earliest phases of the mapping process helped us to anticipate and solve all the major discrepancies between the public and the maps. ${ }^{28}$ We designed a better atlas, and we invited a more suitable public, which brings us to the next section of this movement.

\section{Movement One, Section Three: Design-After-Design and Digital Interactivity}

The third section of the first movement, "design-after-design," has been defined by Ehn as follows:

What we need to do is to design a thing that opens up for potential design after the actual design in the project has taken place, to defer some of the design until later on, assuming that people would be interested in doing that. ${ }^{29}$

While participatory design has long explored how to involve users in the early design stages, ${ }^{30}$ little attention has been dedicated so far to the art of designing visualizations that remain open to subsequent contributions. ${ }^{31}$ Some of this sort of openness has been 
32 One of the best examples of such a strategy has been developed by Bostock and Carter to represent a classic political controversy: the U.S. presidential election. The interactive visualization published by the New York Times is remarkable in that it allows the reader to understand the weight of each swing state by simulating different combinations of results. See www.nytimes.com/interactive/2012/ 11/02/us/politics/paths-to-the-whitehouse.html (accessed October 25, 2014)

33 Jeffrey Heer and Ben Shneiderman, "Interactive Dynamics for Visual Analysis," Queue 10, no. 2 (February 01, 2012): 30.

34 This movement is well synthetized in the mantra, "overview first, zoom and filter, then details-on-demand." Ben Shneiderman, "The Eyes Have It: A Task by Data Type Taxonomy for Information Visualizations," Proceedings of the IEEE Symposium on Visual Languages (1996).

35 cfr. F. Van Ham and A. Perer, "'Search, Show Context, Expand on Demand' Supporting Large Graph Exploration with Degree of Interest," IEEE Transactions on Visualization and Computer Graphics 15 , no. 6 (2009): 953-60. tried in the field of data journalism. Striving to explain complicated affairs while avoiding oversimplification, clever journalists drew on digital interactivity to transfer the simplification work to their readers. ${ }^{32}$

Interactivity is the key to the design-after-design approach (at least in CM). Useful maps give their users the possibility of looking at the bigger picture and focusing on specific details. In traditional cartography, such interactivity is reached by virtue of the extraordinary resolution and flexibility of paper. All travelers know that an atlas is only useful if they can put their finger on it, pull it closer or pull back from it, browse it, twist it, fold it. Navigating by a map always implies navigating through that map.

Inferior in resolution, digital atlases can nonetheless rely on their embedded computation and interaction capabilities. Following Heer and Schneiderman, ${ }^{33}$ the digital atlas should allow users to do the following:

- Focus on the most relevant contents for their analysis by sorting, filtering and deriving/keeping the same data richness but aggregating it at different detail levels.

- Navigate the information space zooming in (users start from a broad view of the topic, drilling down to single elements) ${ }^{34}$ and zooming out (users start from a small portion of the data and then move further out to obtain an overall view on them). ${ }^{35}$

- Validate hypotheses-the interactive map should provide tools to create snapshots of points reached while exploring. In addition, the ability to annotate information, typical of printed artifacts, should be preserved in digital tools.

The three sections of the first movement are very different. In the first, we concatenated a series of maps to deploy complexity in a progressive way. In the second, we learned from participatory design to anticipate users' involvement. In the third, we recognized how digital interactivity could open up controversy atlases to user interaction. In different ways, however, all three sections of the first movement share the same effort to turn the meeting point between public and maps into a meeting process: multiplying the occasions of interaction (section 1), involving the public earlier (section 2), and keeping the maps open longer (section 3). In the following sections, we look at how movements two and three are dedicated to steering this process.

\section{The Second Movement of Controversy Design:}

\section{The Narration-Exploration of Datascape Navigation}

Through the first movement, we moved away from the idea of a punctual equilibrium between complexity and legibility and gained some room to maneuver in the interaction between the maps 
and the users. The second movement is meant to direct such interaction and is twofold, in that interaction with complexity can move in two opposing directions-narration and exploration.

\section{Movement Two, Section One: Narrating Our Way Out of the Labyrinth}

Far from being limited to $\mathrm{CM}$, the narration is common to the largest part of scientific literature. A good scientific paper is not just a pile of facts: It is a good story in the same way a good crime novel is not just a game of clues (which is why we enjoy reading two hundred pages just to discover that the murderer was Colonel Mustard, in the library, with the candlestick).

The content of scientific stories may vary, but the structure remains the same. It always starts with a research question that generates a flourishing of data. Then come the methods and analysis to harness data complexity. Finally, the results are presented, reducing the complications of scientific protocols to a clear and enjoyable story. The same narrative arc should be invoked in CM. Here, the notion of "mapping" falls short in describing our efforts. In cartography, routing is as important as mapping. CM is both the atlas and the finger pointing at it. Just like a good hotel concierge, we cannot just hand over a map to our audience: We have to give them some directions, indicate the attractions, suggest a couple of good restaurants, and in general provide some narration of the city.

\section{Movement Two, Section Two: Exploring Back to Complexity}

If scientific literature is a form of narration, it is nevertheless a very special one. As Latour suggested in a seminal paper on scientific reference, the specialty of scientific stories is their reversibility. ${ }^{36}$ Like every good narration, scientific papers reduce the complexity they address, yet unlike most other narrations, they are always ready to provide details on demand: You don't trust our results? Here is the analysis we followed! You don't trust the analysis? Here is the raw data (or how to obtain it)! This is why scientific papers are persuasive! They allow (even challenge) their readers to verify them. ${ }^{37}$

In $\mathrm{CM}$, in any case, exploration has always been as impor-

37 The possibility of exploring back the validity of a scientific argument becomes more and more prominent now that scientific publications are increasingly migrating to online availability. The decreasing cost of digital publishing now makes possible and even requires that scientists publish their code and data, along with the paper presenting the results extracted from them. Cfr. Ince, Darrel C, Leslie Hatton, and John Graham-Cumming, "The Case for Open Computer Programs," Nature 482, no. 7386 (February 23, 2012): 485-88. tant as narration and for a very simple reason: The method has been developed to address debates that are not yet closed. Describing a controversy is telling a story that does not end at the close of the narration (and further developments might well deny all that was said before). Thus, narration is not enough to tame controversies; exploration is necessary as well.

\section{Movement Two, Section Three: Datascape Navigation}

Making controversies readable while preserving as much as possible of their complexity requires binding together the two 
Figure 8

The circle of datascape navigation through storytelling and exploration. (Daniele Guido, Sciences Po médialab)
38 Bruno Latour, Pablo Jensen, Tommaso Venturini, Sébastian Grauwin, and Dominique Boullier, "'The Whole Is Always Smaller than Its Parts': A Digital Test of Gabriel Tardes' Monads," The British Journal of Sociology 63, no. 4 (December 2012): 590-615.

39 Outstanding examples of the narrationexploration circle exist in the domain of video games (Murray, 1997), and interesting experiments are in progress with web documentaries (e.g., localore.net or webdocu.fr), but little has yet been done in the domain of scientific communication (Edward Segel and Jeffrey Heer, "Narrative Visualization: Telling Stories with

Data," IEEE Transactions on Visualization and Computer Graphics 16, no. 6 (January 2010): 1139-48.

40 T. Kim \& C. DiSalvo, Speculative Visualization: A New Rhetoric for Communicating Public Concerns, Proceedings of Design Research Society (DRS) International Conference Design \& Complexity (Monreal, 2010).

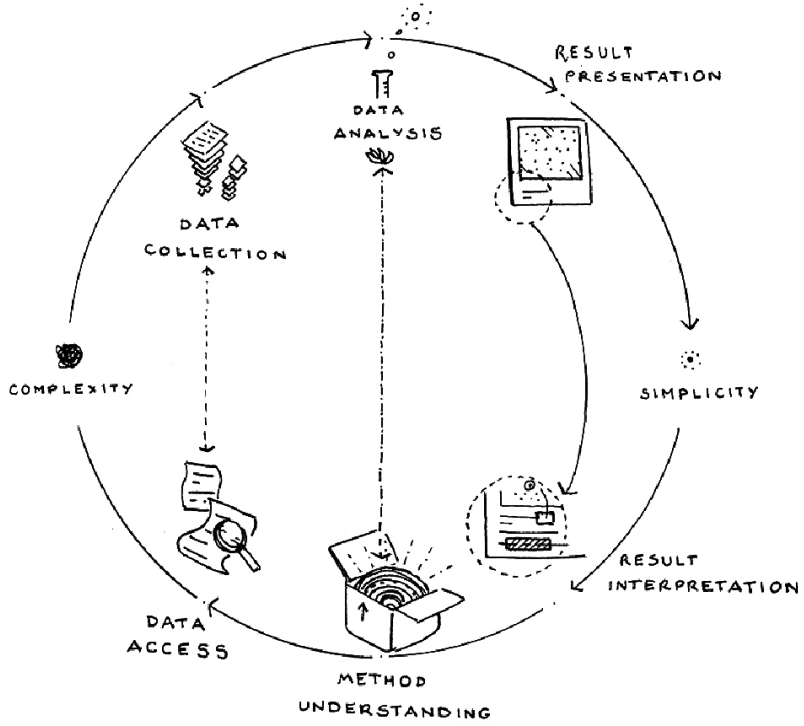

movements of narration and exploration in a circle (as shown in Figure 8). Such a circle offers the public a logical narrative path through the debate, but it also offers the possibility of stepping out at any moment to explore the complexity of controversies. This circulation between complex and simple, data and results, maps and directions has been called datascape navigation,,$^{38}$ and it resumes the second movement of CM. (See Figure 8.)

Implementing such a circle is easier said than done because existing mapping formats are still unable to combine narration and exploration. Linear formats, such as texts or videos, tend to be more suited for narrating stories. Non-linear formats, such as diagrams or websites, do not impose a predetermined path but invite users to explore their richness. The difficulty in overcoming the narration/exploration gap explains why few initiatives have succeeded in combining cinematographic/textual linearity with hypertext openness. ${ }^{39}$

\section{The Third Movement of Controversy Design: The Spiral of Public Engagement}

In submitting the EMAPS project to the European Commission, we knew that $\mathrm{CM}$ was an unconventional object; yet we thought that we could handle it with a conventional approach made of four subsequent phases: data collection, analysis, visualization, and dissemination of results. The first London test, however, made dramatically clear the necessity to replace such a linear organization with a "use-before-use" approach (as described in the second section of the first movement). From the very first test of our project, we were confronted with the need to "engage the public in the process of design-making," as described by Tanyoung Kim and Carl DiSalvo. ${ }^{40}$ 
Figure 9

The stages of the design of a controversy atlas. (Daniele Guido, Sciences Po médialab)
41 Lipmann (1927), and Katz, Elihu, and Paul Lazarsfeld, Personal Influence: The Part Played by People in the Flow of Mass Communications (New Brunswick, NJ: Transaction Publishers, 1955).

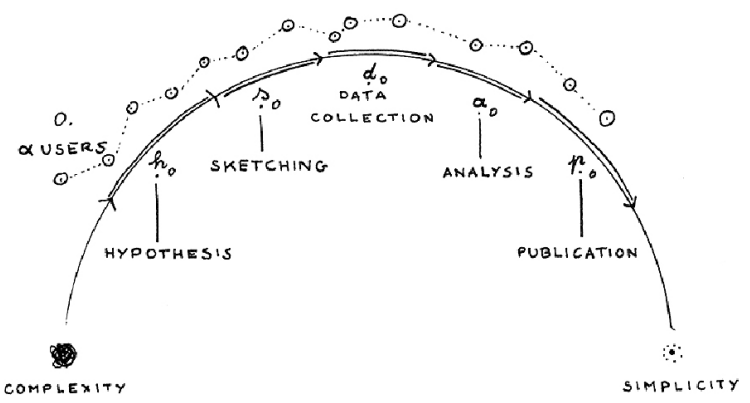

Movement Three, Section One: Engaging the Public Throughout the Mapping Campaign

Far from being restricted to the dissemination phase, contributions from the public are crucial throughout all the phases of controversy mapping:

- Hypothesis. The first phase of all mapping campaigns is a dialogue between users (who identify the interesting research questions for an issue in which they are involved) and data experts (who identify feasible operationalization).

- Sketching. Mockups of the final maps can be very useful to validate operationalization with users and refine the research protocol before actually implementing it.

- Data collection. Users can provide help in collecting data, as they might already have interesting datasets or know where to look for them.

- Analysis. This phase is the only one from which users can be absent (although their presence might offer advantages). In this phase the data experts and design experts realize the maps and interpret them.

- Publication. In the last phase, maps are assembled into atlases, finally ready to be used by the public. (See Figure 9.)

Movement Three, Section Two: Engaging the Public Again, and Again, and Again

After the positive results of the second London meeting, the EMAPS consortium was convinced of the importance of contributions from users and of the fact that the second case study of the project (the debates around climate change adaptation) could not be tackled without an early engagement with the public. Unfortunately, this engagement turned out to be easier said than done. As soon as we decided to "go public," we had to realize that we had little clue as to who the public was. Ready as we were to open the doors of our method, we did not know who to invite in. We were experiencing what media scholars long suggested: There is no such thing as the public. ${ }^{41}$ Publics are always plural and always specialized; they gather temporarily around particular issues to deal with their specific consequences. As Dewey said: 
Figure 10

The three-coils spiral of controversy mappir (Daniele Guido, Sciences Po médialab)
42 Dewey 1946

43 Noortje Marres, No Issue, No Public: Democratic Deficits after the Displacement of Politics (Amsterdam: University of Amsterdam: 2005). Phd by Amsterdam School for Cultural Analysis.

44 In this sense, controversy mapping is not so different from conventional mapping, which has always had a profound effect on geographic territories. Far from being mere representations, maps have always been used to envision how the territories had to be ruled and transformed - for example, when tracing the route of a new road to be built or a new border to be defended (Franco Farinelli, Geografia: Un'introduzione Ai Modelli Del Mondo [Geography: An Introduction to Models of the World] Torino: Einaudi, 2003). On the political use of cartography, see also J W Crampton and John Krygier, "An Introduction to Critical Cartography," ACME: An International E-Journal for Critical Geographies 4, no. 1 (2005).

45 In this sense, our EMAPS project represents a tangible example of the efforts to couple the ideas of John Dewey and the activities of design imagined by Carl DiSalvo, "Design and the Construction of Publics," Design Issues 25, no. 1 (January 2009): 48-63.

46 The progressive approach described here resembles closely the "agile" approach to software development, where drawing detailed and complete specifications is considered less important than prototyping and interacting with the users according to the slogan, "release early, release often!" Eric Raymond, The Cathedral and the Bazaar (Sebastopol, CA: O'Reilly

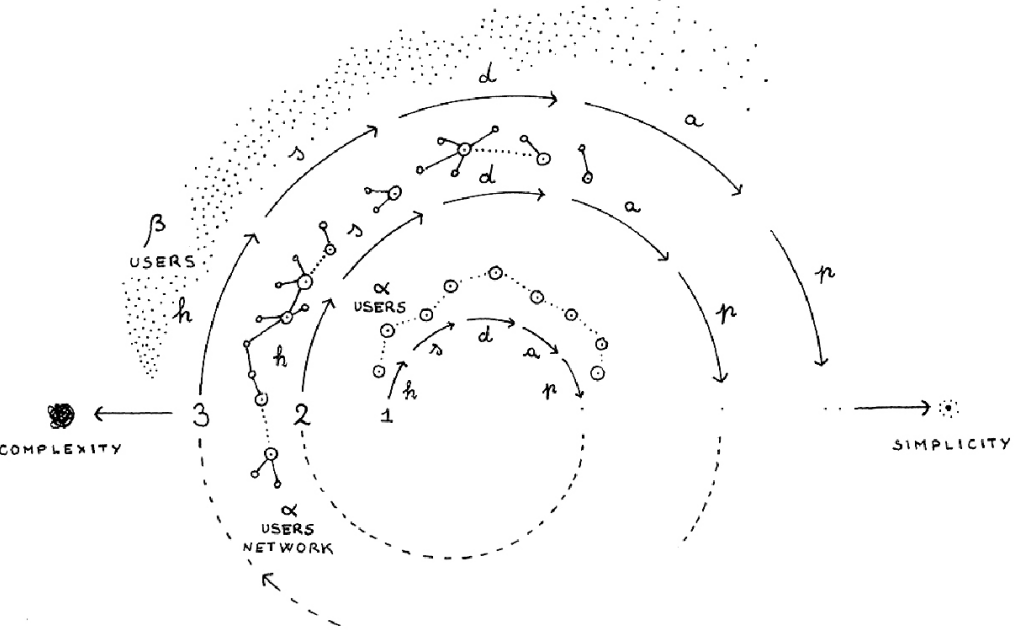

The public consists of all those who are affected by the indirect consequences of transactions to such an extent that it is deemed necessary to have those consequences systematically cared for. ${ }^{42}$

The public of a controversy is nothing other than the assemblage of the actors interested in the debate. To be sure, such an assemblage is neither homogenous nor stable: Publics are summoned by controversies, and their shape depends on how controversies are arranged. "No issue, no public," as Noortje Marres well put it.. ${ }^{43}$

Here, the connection between $\mathrm{CM}$ and its public becomes more complicated. By bringing together diverging viewpoints and arranging them in the same atlas, $\mathrm{CM}$ does more than just describe a state of affairs; it contributes to articulating the debates and arranging their publics. If they want their maps to be politically relevant, social cartographers cannot shy away from the responsibility of transforming the territories they map. ${ }^{44}$ As the EMAPS consortium soon realized, designing relevant maps for the publics and designing relevant publics for the maps are, in fact, one and the same movement. ${ }^{45}$

Such a realization opens yet another riddle: How can we engage a large public without reliable maps to identify it? How can we obtain such a map without the help of a large public? Which rope can we grab to pull ourselves out of our Munchausen's swamp? As in all bootstrapping dilemmas, the solution comes from iteration. We can't design good maps from scratch, nor can we engage large publics out of thin air; but we can design bad maps and then improve them; engage small audiences and then extend them. ${ }^{46}$ (See Figure 10.)

The second section of the third movement, therefore, bends the linear research protocol into a spiral where every coil delivers better maps and engages larger publics. In the EMAPS project, this approach meant finding a few alpha-users willing to help us from the onset of our exploration. The natural choice was to turn to the leaders of other projects already engaged in climate adaptation.

Design/ssues: Volume 31, Number 3 Summer 2015 


1st movement:
Extending the Complexity/Legibility
Trade Off
Trade Off

-1st movement 1st section: Easing into complexity through controversy atlases

a. From statements to debates (the tree of disagreement)

b. From debates to actors (the actors-arguments table)

c. From actors to networks (the actor-network diagram)

d. From networks to cosmos (the scale of dispute)

e. From cosmoses to cosmopolitics (the controversy dynamics)

- 1st movement 2nd section: Use-before-use and participatory design

-1st movement 3rd section: Design-after-design and digital interactivity

$\circ$ 2nd movement 1st section: Narrating the controversy fil-rouge

$\circ$ 2nd movement 2nd section: Exploring the complexity of debate

$\circ$ 2nd movement 3rd section: Datascape navigation

- 3rd movement 1st section: Engaging the public throughout the mapping campaign

$\circ$ 3rd movement 2nd section: Engaging the public again, and again, and again

This first group of alpha-users has helped us to proceed through the first coil of the spiral and develop a first series of maps on the adaptation debate. We hope these maps will be published on the websites of the alpha-users' initiatives and will serve as the starting point of a new iteration with the communities of those initiatives. This second iteration, we also hope, will help us to improve our maps even more, learn about their possible uses, and make them ready to encounter the publics involved in the larger climate adaptation debate.

\section{Conclusion}

In this paper we claim that the exercise of $\mathrm{CM}$ is interesting not in spite of its contradictions but because of them. Resolving such contradictions is less a question of balance than of movement. In fact, mapping controversies for their publics entails three main movements, each with several sub-sections, as shown in Figure 11.

These movements, to be sure, are not the only ones possible, and others might be proposed to guide CM. However, alternative movements would have to provide the same articulations described here: to deploy gradually the complexity of public disputes; to engage the public from the beginning and leave the design open at the end of the cartographic campaign; to offer linear the story of the controversy while allowing detours and exploration; and to design ever better maps and engage ever larger publics.

Conceptualizing CM in terms of movement allows us to answer a question that is often asked about it: What is the most important part of the cartographic exercise-the product or the process, the map or the mapping? This paper explains that there is, in fact, little difference between the two. CM is neither a product nor a process, but a movement or more exactly, a series of movements. In this paper, we have proposed a vocabulary to talk about these movements. Inventing concrete ways to implement them is the goal of EMAPS and the CM projects that will follow it. 